\title{
Geopolymer: a review on physical properties of inorganic aluminosilicate coating materials
}

\begin{abstract}
Geopolymer is a potential material that can be used in many forms of applications such as for building, automotive, aerospace, and many more. It exhibits many excellent physical, thermal and chemical properties. Geopolymer material provides a cost effective and sustainable solution by recycle the hazardous residue material and it undergone green chemistry technique treatment. Geopolymerization process involves combination mixture of aluminosilicate from natural mineral or industrial waste such as fly ash or slag or rice husk ash with activated alkaline solution. This review paper exclusively explore more on the interfacial adhesion of geopolymer coating on substrate surface, effect of coating thickness and filler inclusion in geopolymer matrix system. Literature demonstrates that type of substrate and substrate surface plays a crucial role for good interfacial adhesion with geopolymer materials. In addition, coating thickness will affect the insulating capacity performance, while inclusion of filler can reduce the coating shrinkage problem.
\end{abstract}

Keyword: Adhesion; Al Ratio; Alumino-Silicate; Coating; Geopolymer; Si Ratio 